\title{
Can IT Prototyping Enhance Business School Education?
}

\author{
Jacqueline Wong and Timon Du \\ Department of Decision Sciences and Managerial Economics, \\ The Chinese University of Hong Kong, Shatin, NT, \\ Hong Kong, China
}

\author{
jacquelinewong@cuhk.edu.hk timon@cuhk.edu.hk
}

\begin{abstract}
In business school, students must learn essential communication, analytical, and problem-solving skills. In this study, we examine whether the prototyping project in our computer-based information system (CBIS) course enhances these three essential skills. The prototyping process, taught with an information system approach, is the focus of our project-centered teaching method. The pedagogy uses a system development life cycle model to define problems and to analyze, design, and develop computer systems. A questionnaire administered to 184 students who had taken the course suggests that the CBIS course improves communication skills and problemsolving skills than on analytical skills. The prototyping project does not enhance analytical skills, but does significantly enhance communication skills and problem-solving skills. These findings can help to improve the teaching of CBIS to business school students.
\end{abstract}

Keywords: Computer-based information system, Prototyping, Communication skills, Analytical skills, Problem-solving skills

\section{Introduction}

In their book "Higher Education of Business," Gordon and Howell (1959) emphasized that business schools in higher education should provide better quality education than provisional schools. What are the educational goals that lead to high quality business education? The goals of our undergraduate programs are to teach students (i) effective business communication skills; (ii) effective analytical skills that support decision-making; (iii) the ability to integrate business knowledge and to solve problems in a business environment; (iv) the ability to propose strategies in a global environment; (v) awareness of ethical issues in a business context; and (vi) specific knowledge in one or more functional areas of business management.

Material published as part of this publication, either on-line or in print, is copyrighted by the Informing Science Institute. Permission to make digital or paper copy of part or all of these works for personal or classroom use is granted without fee provided that the copies are not made or distributed for profit or commercial advantage AND that copies 1) bear this notice in full and 2) give the full citation on the first page. It is permissible to abstract these works so long as credit is given. To copy in all other cases or to republish or to post on a server or to redistribute to lists requires specific permission and payment of a fee. Contact Publisher@InformingScience.org to request redistribution permission.
A school's educational goals should lead to graduate employability. Kavanagh and Drennan, (2008) pointed out that employers expect their employees to have excellent communication, analytical, professional, business-awareness, and teamwork skills. Andrews and Higson (2008) suggested that employers want business school students to have hard business-related knowledge and skills; soft business-related skills; and 
work experience and work-based learning. Alternatively, these can be called analytical skills, communication skills, and problem-solving skills, respectively. If we match the goals of our undergraduate programs with the skills that lead to graduate employability, we can see that soft business-related skills (communication skills) are related to (i) effective business communication skills and (iv) the ability to propose strategies in a global environment. In contrast, business specific issues such as hard business-related knowledge and skills (analytical skills) are attained though (ii) effective analytical skills for decision-making and (vi) specific knowledge in one or more functional areas of business management. Similarly, work experience and work-based learning (problem-solving skills) are derived from (iii) the ability to integrate business knowledge and solve problems in a business environment, and (v) the awareness of ethical issues in a business context. Figure 1 presents a model of these relationships.

- Effective business communication skill

- Ability to propose strategies in a global environment

\section{-}

然

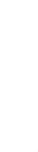

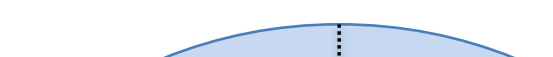

$+$
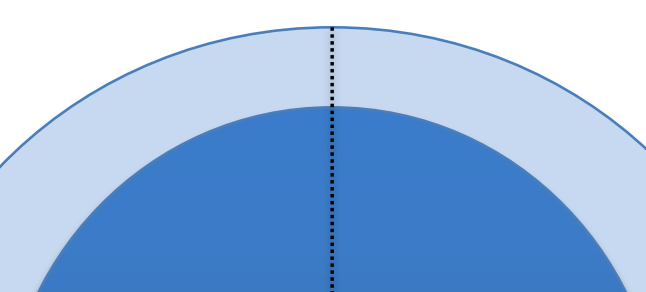

- Effective analytical skills that support decision-making

- Specific knowledge in one or more functional areas of business management

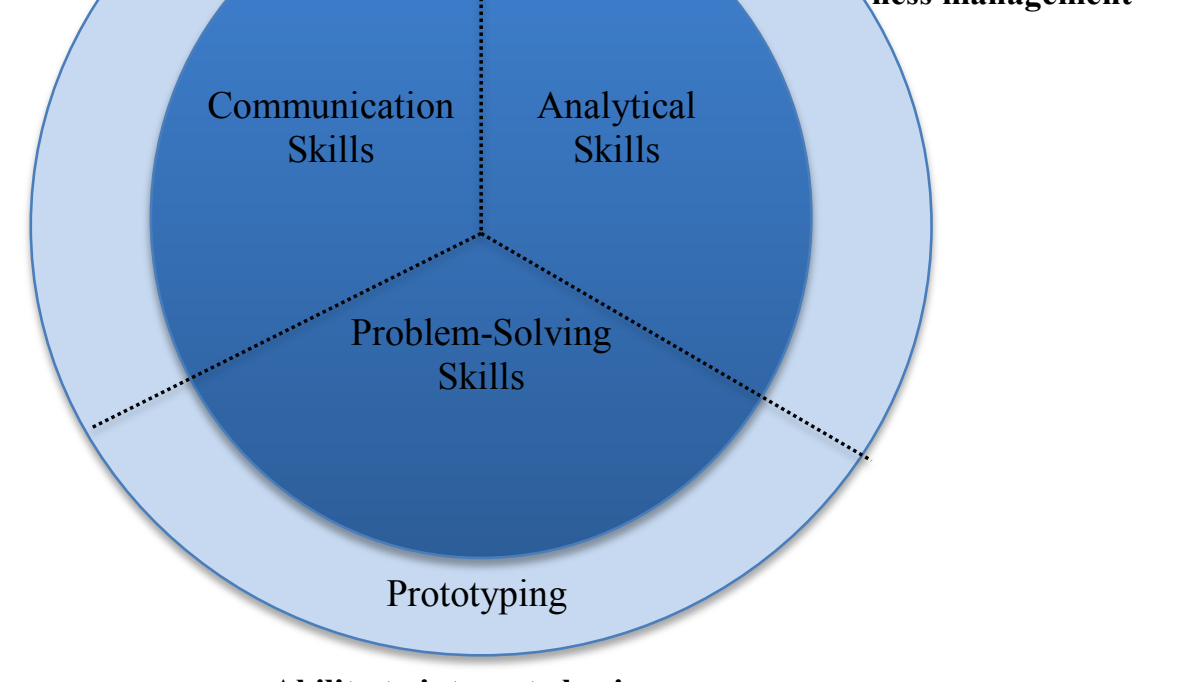

- Ability to integrate business knowledge and to solve problems in a business environment

- Awareness of ethical issues in a business context

\section{Figure 1 Mapping employability skills with education goals in a business school.}

A computer-based information system course (CBIS) that teaches computers, information technology, and software development to students is a required, but not always popular, subject in business schools. Conventional subject-oriented approaches designed for computer engineering students do not fit the needs and interests of business school students. Our experience has shown that a project-centered teaching approach is effective for teaching IT knowledge to business school students (Wong \& Du, 2003). The approach asks students to identify and solve a real- 
world IT problem and uses the project to encourage active involvement in the whole learning process. Our 14-week computer-based information system course adopts a system development life cycle model with 10 phases. As the students have a self-chosen real-world project to focus on, they are eager to learn the skills that can help them to solve their problems. This approach changes the conventional one-way lecturing relationship between teacher and students, and the instructor becomes both a teacher and a mentor. It can be considered another way of flipping a class. The grading scheme includes a group-based laboratory test, group-based in-class assignment, investigation report, project proposal, project presentation, final documentation, and final examination. Moreover, as we argue in this study, a well-designed project-centered CBIS course may also effectively enhance students' communication, analytical, and problem-solving skills.

In project-centered teaching, resource limitations and time constraints usually mean that even real-world projects normally end with the presentation of a prototype. Building a prototype gives students a systematic way of integrating knowledge from investigation, system analysis, system design, and system development. A successful prototype requires communication, analytical, and problem-solving skills. In this study, we examine whether building a prototype teaches these three skills. Specifically, we examine whether prototyping a Web-based information system enhances a student's ability to propose strategies in a global environment (communication skills); to learn specific knowledge in one or more functional areas of business management (analytical skills); and to increase their awareness of ethical issues in a business context (problem-solving skills).

\section{Related Works}

The conventional pedagogy in Asian schools emphasizes analytical skills, partly because the results can be relatively easily measured. Although the new trend in business school education is to emphasize soft skills, hard business knowledge and training are still the foundation that employees need to carry out their jobs. Thus, it is vital that a CBIS course offered to business school student teaches analytical skills.

Barrett (2006) found that a manager spends about 70 to 90 percent of his or her time every day in communication. Communication skills are the most important skills a manager must possess. Senior executives who want to be effective leaders need communication skills more than any other skill. That is, the ability to communicate with others is one of the most important skills to teach business school students (Milam and Martin, 1994). Experiential modes of learning are suitable for teaching skills such as networking skills or leadership (Whitley, 1989). These skills are difficult to teach in conventional classrooms, especially as faculty members are often hired because of their strong theoretical and analytical skills (Pferffer and Fong, 2002). Project teams can provide experiential modes of learning that teach students about internal communication with team members and external communication with clients. Communication in teams formed of people who complement each other can improve productivity (Scarfino and Roever, 2009). Martins and Kellermanns (2004) used Web-based technology to free up class time for students to work on interpersonal and communication skills. However, to help students acquire knowledge about system development, face-to-face learning is necessary, as pure online instruction is insufficient for teaching analytical skills (Santos \& Wright, 2001).

Uncertainty, difficulties, or even assignments and tasks are part of ordinary workdays. We may encounter problems at any moment. Educators agree that equipping business school students with good problem-solving skills is crucially important, as strong problem-solving skills can improve careers. Many sources have made suggestions for improving students' problem-solving skills. For example, case study approaches enable students to develop both analytical and problem-solving skills (Gibb, 1996). Bigelow (2004) used a 7-step problem-based learning model to help students acquire problem-solving skills and basic knowledge. 
It has been shown that a CBIS course can enhance essential skills. For example, Aesaert and Braak (2014) found that pupils' ICT self-efficacy positively influenced their analytical intelligence, control learning style, and amotivation. Amotivation is caused by feelings of incompetence and a lack of control (Vallerand, 1992). Wang, et al. (2014) discovered that some types of social network sites (SNS) have a positive effect on users' well-being, but do not improve the quality of friendship among college students. Lin, et al. (2014) analyzed Facebook emotional disclosure and found that users with denser networks disclosed more positive and negative emotions, although the amount of disclosure was also mediated by the need for emotional expression.

The system development life cycle includes five phases: system planning, system analysis, system design, system implementation, and system support. In classrooms, due to limited resources, time, and programing skills, it is not feasible to provide training in the last two phases. Thus, in a class project students are normally expected to develop a prototype, but not to implement a real system and provide support for it. In the system development cycle, the crucial steps of system design are developing source documents, layouts for system users for inputs and output, and database management (Whitten \& Bentley, 2005). Prototyping is an essential step between system design and development that converts concepts into a system. Budde et al. (2011) considered prototyping an evolutionary system development approach for constructing and evaluating models. Many systems developed from new concepts rely on prototyping. For example, Ahsan, McManis, and Hashmi (2014) built a prototype for intelligent vehicle speed monitoring and management. Argoty and Figueroa (2014) developed a prototype for an interactive hospital room with natural interaction devices. Ayer, Messner, and Anumba (2014) presented a workflow model for a mobile computer-based prototype for architectural engineering students. According to the MerriamWebster dictionary, a prototype is a full-scale of model or example that exhibits the essential features of a design. Modeling and providing examples are the results of system analysis and this demands analytical skills. Exhibition, however, is a form of communication that requires communication skills. Finally, problem-solving skills are needed to derive a model's essential features though complete system planning, analysis, and design. As a result, prototyping is a skill that integrates many indispensible business skills.

\section{Research Method}

Andrews and Higson (2008) argued that business schools should provide students with three major skills for graduate employability: interpersonal and communication skills, analytical skills, and problem-solving skills. Extending our previous study of project-centered teaching (Wong \& $\mathrm{Du}, 2003$ ), we designed a CBIS course based on real-world group projects that contained the following 10 phases: form a team, solicit clients (each group uses their own personal network to find a client from the business world), research the project, conduct group meetings, design a database, organize a lab test to drive the system analysis, work on in-class assignments, review project with instructors, present project, and arrange a Q\&A session for peers after the project presentation. We asked students to identify which phases were most helpful in developing specific skills. Tables 1 to 3 list the items (phases) measured on a 5-point Likert scale, ranging from "most helpful" (1) to "least helpful" (5). 
Table 1 Items for measuring communication skills

\begin{tabular}{ll}
\hline A & Effective business communication skills \\
\hline A1 & Forming a BIG group (8-10 persons) \\
A2 & Communicating with your client \\
A3 & Doing research for your project \\
A4 & Group meeting \\
A5 & Lab test \\
A6 & In-class assignment \\
A7 & Project review \\
A8 & Project presentation \\
A9 & Q\&A on the project presentation \\
\hline
\end{tabular}

Table 2 Items for measuring analytical skills

\begin{tabular}{ll}
\hline B & Effective analytical skills that support decision-making \\
\hline B1 & Studying the daily operation of your client's company \\
B2 & Creating a database \\
B3 & Doing research for your project \\
B4 & Communicating with your client \\
B5 & Group meeting \\
B6 & Lab test \\
B7 & In-class assignment \\
B8 & Project review \\
B9 & Project presentation \\
B10 & Q\&A on the project presentation \\
\hline
\end{tabular}

Table 3 Items for measuring hard business knowledge and problem-solving skills

$\mathrm{C}$ Increase your ability to integrate business knowledge and solve problems in a business environment

\begin{tabular}{ll}
\hline C1 & Communicating with your client \\
C2 & Preparing your investigation report \\
C3 & Creating a database \\
C4 & Doing research for your project \\
C5 & Group meeting \\
C6 & Lab test \\
C7 & In-class assignment \\
C8 & Project review \\
C9 & Project presentation \\
C10 & Q\&A on the project presentation \\
\hline
\end{tabular}


As discussed, prototyping is a systematic method for enhancing communication, analytical, and problem-solving skills. To verify the success of prototyping as a teaching method, students were asked which of the following 10 steps helped them to improve their advanced communication, analytical, and problem-solving skills: system investigation process, system analysis, system design, doing research, group meeting, lab test, in-class assignment, project review, project presentation, and $\mathrm{Q} / \mathrm{A}$ in the project presentation. The items used in the survey are shown in Tables 4 to 6.

Table 4 Items for measuring advanced communication skills.

\begin{tabular}{ll}
\hline D & $\begin{array}{l}\text { Building a prototype to increase your ability to propose strategies in a global envi- } \\
\text { ronment }\end{array}$ \\
\hline D1 & System investigation process \\
D2 & System analysis \\
D3 & System design \\
D4 & Doing research for your project \\
D5 & Group meeting \\
D6 & Lab test \\
D7 & In-class assignment \\
D8 & Project review \\
D9 & Project presentation \\
D10 & Q\&A on the project presentation \\
\hline
\end{tabular}

Table 5 Items for measuring advanced problem-solving skills.

\begin{tabular}{ll}
\hline E & Building a prototype to increase your awareness of ethical issues in a business context \\
\hline E1 & System investigation process \\
E2 & System analysis \\
E3 & System design \\
E4 & Doing research for your project \\
E5 & Group meeting \\
E6 & Lab test \\
E7 & In-class assignment \\
E8 & Project review \\
E9 & Project presentation \\
E10 & Q\&A on the project presentation \\
\hline
\end{tabular}


Table 6 Items for measuring advanced analytical skills.

\begin{tabular}{ll}
\hline F & $\begin{array}{l}\text { Building a prototype to learn specific knowledge in one or more functional areas of } \\
\text { business management }\end{array}$ \\
\hline F1 & System investigation process \\
F2 & System analysis \\
F3 & System design \\
F4 & Doing research for your project \\
F5 & Group meeting \\
F6 & Lab test \\
F7 & In-class assignment \\
F8 & Project review \\
F9 & Project presentation \\
F10 & Q\&A on the project presentation \\
\hline
\end{tabular}

\section{Data Analysis}

The sample consists of undergraduate students who completed the Information Systems and ECommerce course at a respected university in the 2011/2012 academic year. The course is a required course offered to business school students in the integrated business administration curriculum. Out of 196 returned forms, 9 were missing one item, 2 were missing the answers on the second page, and 1 had no student ID, leaving 184 valid questionnaires. The average scores of the six constructs (see Tables $1-6$ ) are shown in Table 7.

Table 7 Average scores of the six skills constructs.

\begin{tabular}{|l|l|l|l|l|l|l|}
\hline Construct & A & B & C & D & E & F \\
\hline Avg. & 2.1202 & 2.2057 & 2.1491 & 2.2372 & 2.5903 & 2.1578 \\
\hline Rank & 1 & 4 & 2 & 5 & 6 & 3 \\
\hline
\end{tabular}

We first investigate whether there is a difference between the constructs, i.e., $\mathrm{H}_{0}: \mu_{1}=\mu_{2}=\mu_{3}=$ $\mu_{4}=\mu_{5}=\mu_{6}$. The one-way ANOVA result (F Value at 72.31 and $\operatorname{Pr}<2 \mathrm{e}-16$ ) indicates this hypothesis is rejected.

Next, we use the Welch Two Sample t-test to compare the differences between the three basic skills. Note that the scale ranges from 1, "very helpful," to 5, "least helpful." The results show that students think the CBIS course improves their communication, analytical, and problemsolving skills $(2.1202,2.2057,2.1291$, respectively), but, as the averages are close to 2.5 , or neutral, they do not think the course makes large improvements in these skills. We compare the constructs $\mathrm{A}$ and $\mathrm{B}$; $\mathrm{B}$ and $\mathrm{C}$; and $\mathrm{A}$ and $\mathrm{C}$. The results reject the hypothesis $\mathrm{H}_{0}$ that there is no difference between A and B $(t=-2.9059$, d.f. $=3670.542$, and $p$-value $=0.001842)$; fails to reject the hypothesis $\mathrm{H}_{0}$ that there is no difference between $\mathrm{A}$ and $\mathrm{C}$ at the $99 \%$ confidence level $\mathrm{t}=-$ 0.985 , d.f. $=3659.767$, and $p$-value $=0.1623)$; and rejects the hypothesis $\mathrm{H}_{0}$ that there is no difference between $\mathrm{B}$ and $\mathrm{C}(\mathrm{t}=-2.0026, \mathrm{df}=3915.412$, and $\mathrm{p}$-value $=0.02264)$. This indicates that 
the course has more effect on communication skills and problem-solving skills than on analytical skills.

Next, we use the Welch Two Sample t-test to compare the differences between the three basic skills and the advanced skills. That is, we compare $\mathrm{A}$ and D; B and F; and $\mathrm{C}$ and $\mathrm{E}$. The results reject the hypothesis $\mathrm{H}_{0}$ that there is no difference between $\mathrm{A}$ and $\mathrm{D}(\mathrm{t}=-4.0009$, d.f. $=3656.949$, and $\mathrm{p}$-value $=3.217 \mathrm{e}-05)$; fail to reject the hypothesis $\mathrm{H}_{0}$ that there is no difference between $\mathrm{B}$ and $\mathrm{F}$ at the $99 \%$ confidence level $(\mathrm{t}=-1.6492$, d.f. $=3908.819$, and $\mathrm{p}$-value $=0.04959)$; and reject the hypothesis $\mathrm{H}_{0}$ that there is no difference between $\mathrm{C}$ and $\mathrm{E}(\mathrm{t}=-15.0013$, d.f. $=3888.353$, and $\mathrm{p}$-value $<2.2 \mathrm{e}-16)$. These findings suggest that the CBIS course has more effect on construct A (communication skills) and construct C (problem-solving skills) than on construct B (analytical skills). However, prototyping does not further enhance communication skills (from 2.1202 to 2.2372 ) or problem-solving skills (2.1491 to 2.5903). Moreover, we cannot prove it enhances analytical skills (2.2057 and 2.1578).

Building a prototype is the last step in the class and is approached from a system perspective. Thus, it is fair to examine only the first three items used to measure constructs D, E, and F to see how building a prototype helps to teach communication, analytical, and problem-solving skills. The data show an average of 2.13, 2.54, and 2.00 for constructs D, E, and F, respectively. Therefore, we separate those items dedicated for system prototyping, i.e. D1, D2, and D3 in construct D, from the rest of items to estimate the loadings of path coefficients between construct A and D' (a new construct without D1, and D2, and D3), between P (a new construct includes D1, D2, and D3) and $\mathrm{A}$, and between $\mathrm{P}$ and $\mathrm{D}$ ' using linear structural relations (LISREL). We found that the estimation between $\mathrm{P}$ and $\mathrm{A}$ is $0.474(\mathrm{t}=6.342)$, between $\mathrm{P}$ and $\mathrm{D}^{\prime}$ is $0.273(\mathrm{t}=3.342)$, and between $A$ and $D^{\prime}$ is $0.603(t=4.118)$. The fit indices AGFI $=0.84$, RMSEA $=0.06$, and Bentler comparative Fit $=0.97$ show a good fit. This confirms the IT prototyping can enhance communication skills.

Similarly, we separate those items dedicated for system prototyping, i.e. E1, E2, and E3 in construct $\mathrm{E}$, to estimate the loadings of path coefficients between construct $\mathrm{C}$ and $\mathrm{E}$, , between $\mathrm{P}$ (a new construct includes E1, E2, and E3) and C, and between P and E'. We found that the estimation between $\mathrm{P}$ and $\mathrm{C}$ is $0.512(\mathrm{t}=8.320)$, between $\mathrm{P}$ and $\mathrm{E}^{\prime}$ is $0.789(\mathrm{t}=13.256)$, and between $\mathrm{C}$ and $\mathrm{E}^{\prime}$ is $0.225(\mathrm{t}=4.442)$. The fit indices AGFI $=0.82$, RMSEA $=0.07$, and Bentler comparative Fit $=0.97$ show a good fit. This confirms the IT prototyping can enhance problem-solving skills.

The average scores of the items used to measure each construct are shown in Table 8. According to the students, the steps that improve communication skills are A1 (form an 8-10 person group) and A6 (in-class assignment). B3 (doing research for your project) is the most useful step for improving analytical skills, and C5 (group meeting) is the most helpful step for improving problemsolving skills. The model was

We note that prototyping improves communication skills (construct D), whereas system design (D3) is the most useful step for improving one's ability to propose strategies in a global environment, and lab tests (D6) are the least useful for developing this skill. Similarly, within the problem-solving skills (construct E), doing research for your project (E4) is the most helpful step for improving awareness of ethical issues in a business context and lab tests (E6) are the least useful. Finally, for advanced analytical skills (construct F), system analysis (F2) and doing research for your project (F4) improve learning in one or more functional areas of business management, whereas lab tests (F6) do not contribute to this skill. 
Table 8 Average scores of items in constructs.

\begin{tabular}{|c|c|c|c|c|c|c|c|c|c|c|c|}
\hline Item & A1 & A2 & \multicolumn{2}{|c|}{ A3 } & A4 & \multicolumn{2}{|c|}{ A5 } & A6 & A7 & A8 & A9 \\
\hline Avg. & 2.041 & 2.449 & & & & & & 2.041 & 2.102 & 2.071 & 2.102 \\
\hline Rank & 1 & 9 & 8 & 5 & & 3 & & 2 & 6 & 4 & 6 \\
\hline Item & B1 & B2 & B3 & B4 & B5 & & B6 & B7 & B8 & B9 & B10 \\
\hline Avg. & 2.13 & 2.15 & 2.02 & 2.45 & 2.2 & & 2.25 & 2.17 & 2.19 & 2.29 & 2.21 \\
\hline Rank & 2 & 3 & 1 & 10 & 6 & & 8 & 4 & 5 & 9 & 7 \\
\hline Item & $\mathrm{C} 1$ & $\mathrm{C} 2$ & C3 & C4 & $\mathrm{C5}$ & & C6 & C7 & C8 & C9 & C10 \\
\hline Avg. & 2.44 & 2.09 & 2.22 & 2.10 & 2.0 & & 2.10 & 2.06 & 2.14 & 2.22 & 2.11 \\
\hline Rank & 10 & 3 & 9 & 4 & 1 & & 5 & 2 & 7 & 8 & 6 \\
\hline Item & D1 & D2 & D3 & D4 & D5 & & D6 & D7 & D8 & D9 & D10 \\
\hline Avg. & 2.21 & 2.16 & 2.03 & 2.16 & 2.2 & & 2.42 & 2.35 & 2.30 & 2.18 & 2.32 \\
\hline Rank & 5 & 3 & 1 & 2 & 6 & & 10 & 9 & 7 & 4 & 8 \\
\hline Item & E1 & E2 & E3 & E4 & E5 & & E6 & E7 & E8 & E9 & E10 \\
\hline Avg. & 2.56 & 2.53 & 2.55 & 2.38 & 2.5 & & 2.90 & 2.80 & 2.46 & 2.61 & 2.58 \\
\hline Rank & 6 & 3 & 5 & 1 & 3 & & 10 & 9 & 2 & 8 & 7 \\
\hline Item & F1 & F2 & F3 & $\mathrm{F} 4$ & F5 & & F6 & F7 & F8 & F9 & F10 \\
\hline Avg. & 2.04 & 1.93 & 2.04 & 1.96 & 2.2 & & 2.43 & 2.30 & 2.21 & 2.19 & 2.27 \\
\hline Rank & 3 & 1 & 4 & 2 & 6 & & 10 & 9 & 6 & 5 & 8 \\
\hline
\end{tabular}

\section{Conclusions}

This study analyzes the skill sets of 184 university business school students who took a required course in computer-based information system (CBIS). The data is from a questionnaire that asked students which of the course components best teaches communication, analytical, and problemsolving skills, which are considered critical skills for employability. The CBIS course not only covers essential IT knowledge and skills, it also encourages students to integrate the topics covered in class by developing a Web-based information system. Due to limitations in time and experience, the class only takes the system development process to the prototyping stage. This study explores whether the process of developing a prototype enhances the three essential skills all business students need. The results are as follows.

A CBIS course is more effective in teaching communication and problem-solving skills than in teaching analytical skills.

Building prototypes does not enhance analytical skills.

Building prototypes significantly enhances problem-solving skills and communication skills.

Of the 10 course stages (items), system design (D3) builds communication skills, research (E4) builds problem-solving skills, and both system analysis (F2) and research (F4) build analytical skills. The lab test (F6) contributes the least to skill development. 


\section{Discussion, Limitations, and Future Research}

CBIS is not always a popular course among business students. However, a CBIS course that uses a system development life cycle model can help students develop communication, analytical, and problem-solving skills. Thus, a CBIS course that takes an IT project-centered approach can assist students to learn both essential computer system knowledge and the skills needed for graduation compatibility.

Due to resource limitations and time constraints, most CBIS courses stop at the prototyping stage of the product development life cycle. However, building a prototype is a systematic way to integrate advanced skills. Specifically, we expect students who complete our course to have effective business communication skills, effective analytical skills that support decision-making, the ability to integrate business knowledge and solve problems in a business environment, the ability to propose strategies in a global environment, awareness of ethical issues in a business context, and specific knowledge in one or more functional areas of business management. The first three goals of our course are to enhance communication skills, to improve analytical skills, and to develop problem-solving skills. Specifically, the course increases students' ability to propose strategies in a global environment, which is a communication skill; increases their awareness of ethical issues in a business context, which is a problem-solving skill; and teaches them specific knowledge in one or more functional areas of business management, which improves their analytical skills. We also argue that an awareness of ethical issues and the ability to position oneself with regards to this issues, demands advanced problem-solving skills.

Given the above argument, we assume that prototyping a Web-based information system can also help to achieve the three advanced goals. Our findings show that CBIS course has more effect on communication skills and problem-solving skills than on analytical skills. Also, the process of building a prototype can significantly enhance communication skills and problem-solving skills. The team-based IT prototyping enhances the communication skills that is in line with (Lin, et al., 2014) and (Wang, et al., 2014). However, the course does not significantly improve the analytical skills contradicting the findings in (Aesaert \& Braak, 2014) that used pupils as the research subjects.

Building a prototype is a systematic way to integrate the various topics taught in a CBIS course. The process is most effective at enhancing problem-solving skills and communication skills, and only has a small effect on analytical skills, probably because business clients normally have lower expectations of student projects. The prototype process ends with the demonstration of the concept in a prototype. If the prototype were developed into a full-scale system, students might encounter more problems than they anticipated in the prototyping stage, including financial and human resources issues. Solving such problems would require good problem-solving skills and analytical skills. However, due to limited time, resources, and skills, the projects are not extended beyond the prototyping stage, and these issues are therefore not addressed in the class. The same issues and opportunities would occur in the technical support stage of a real-world system development life cycle.

This study has several limitations. CBIS courses focus on the prototyping phase of product development, so the skills learned in later stages are not covered in the course. Furthermore, we ask students to design real-world projects, and as a result the difficulty of the projects varies, and this increases the variance in this study. Also, the mix of students varies between groups, introducing another variable into the study. Furthermore, as CBIS is a required course, many topics need to be covered in the 14-week class and students with a wide range to abilities take the class together.

This study examines whether a class centered on building a prototype helps business students achieve their learning goals. The results show that building a prototype can significantly enhance communication or problem-solving skills, but not analytical skills. The results of the question- 
naire suggest that students slightly agree that the course effectively teaches these skills. Future studies should consider how to improve the teaching of communication, problem-solving, and analytical skills, as well as other skills.

In this study, we define prototyping as a process that integrates problem definition, system investigation, system planning, and system design. Future studies should develop an instrument for measuring prototyping skills. Similarly, items could also be developed for measuring problemsolving, analytical, and communication skills. Better measurement tools would make it possible to use structural equation modeling to examine the relationships between skills. Moreover, we could also study the effect of prototyping on other learning factors.

\section{References}

Aesaert, K., et al. (2014). Direct measures of digital information processing and communication skills in primary education: Using item response theory for the development and validation of an ICT competence scale, Computers \& Education, 76, 168-181.

Aesaert, K. \& Braak, J. (2014). Exploring factors related to primary school pupils' ICT self-efficacy: A multilevel approach, Computers in Human Behavior, 41, 327-341.

Ahsan, M., McManis, J., \& Hashmi, M. S. J. (2014). Prototype system development for wireless vehicle speed monitoring. 9th International Symposium on Communication Systems, Networks \& Digital Sign (CSNDSP), 287-292.

Aiken, M., \& Martin, J. (1994). Requisite skills of business school graduates: Perceptions of senior corporate executives. Journal of Education for Business, 69(3), 159-162.

Andrews, J., \& Higson, H. (2008). Graduate employability, 'soft skills' versus 'hard' business knowledge: A European study. Higher Education in Europe, 33(4), 411-422.

Argoty, J. \& Figueroa, P. (2014). Design and development of a prototype of an interactive hospital room with Kinect. INTERACCIÓN 2014, September10-12, Puerto de la Cruz, Tenerife, Spain.

Ayer, S. K., Messner, J. I., \& Anumba, C. J. (2014). Development of ecoCampus: A prototype system for sustainable building design education. ITcon, 19, 520-533. Retrieved from http://www.itcon.org/2014/30

Barrett, D. J. (2006). Strong communication skills a must for today's leaders. Handbook of Business Strategy, 7(1), 385-390.

Bigelow, J. D. (2004). Using problem-based learning to develop skills in solving unstructured problems, Journal of Management Education, 28, 591-609.

Budde, R. et al. (2011). Prototyping: An approach to evolutionary system development, Springer Publication Incorporated.

Dos Santos, B. L., \& Wright, A. L. (2001). Internet-supported management education. Information Services \& Use, 21, 53-64.

Gibb, A. (1996). Entrepreneurship and small business management: Can we afford to neglect them in the twenty-first century business school? British Journal of Management, 7(4), 309-321.

Gordon, R. A. \& Howell. J. E. (1959). Higher education for business. New York: Columbia University Press.

Kavanagh, M. \& Drennan, L. (2008). What skills and attributes does an accounting graduate need? Evidence from student perceptions and employer expectations. Accounting and Finance, 48, 279-300.

Lin, H., Tov, W., \& Qiu. L. (2014) Emotional disclosure on social networking sites: The role of network structure and psychological needs. Computers in Human Behavior, 41(December), 342-350.

Martins, L. \& Kellermanns, F. (2004). A model of business school students' acceptance of a Web-based course management system. Academy of Management Learning and Education, March 1, 3(1), 7-26. 
Pferffer, J. \& Fong, C. (2002). The end of business schools? Less success than meets the eye. Academy of Management Learning and Education, 1(1), 78-95.

Scarfino, D. \& Roever, C. (2009). Team-building success: It's in the cards. Business Communication Quarterly, 72(1), 90-95.

Vallerand, R. J., et al. (1992). The academic motivation scale - A measure of intrinsic, extrinsic, and amotivation in education. Educational and Psychological Measurement, 52(4), 1003-1017.

Wang J., et al. (2014). The effects of social networking site (SNS) use on college students' friendship and well-being. Computers in Human Behavior, 37, 229-236.

Whitley, R. (1989). On the nature of managerial tasks and skills: Their distinguishing characteristics and organization. Journal of Management Studies, 26(3) May, 209-224.

Whitten, J. \& Bentley, L. (2005). System Analysis and Design Method (5th ed.). McGraw-Hill.

Wong J., \& Du, T. (2003). Project-centered teaching on CBIS to IBBA students in Hong Kong, inroads The SIGCSE Bulletin, 35(4), December, 35-38.

\section{Biographies}

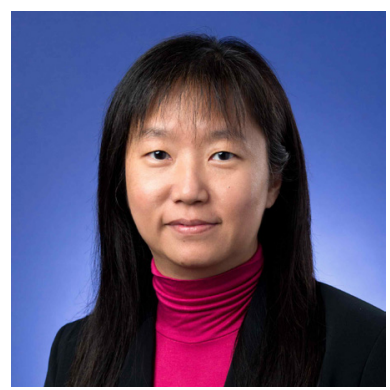

Jacqueline Wong obtained her MPhil and $\mathrm{PhD}$ degrees in Computer Science from The Chinese University of Hong Kong, Hong Kong. Dr. Wong is a Senior Lecturer at the Chinese University of Hong Kong. Her research interests include information anc communication technology in education and information retrieval.

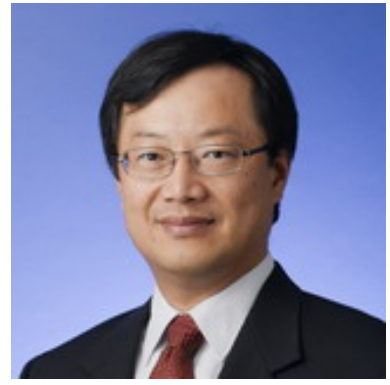

Timon. C. Du. obtained his MS and PhD degrees in Industrial Engineering from Arizona State University, USA. Dr. Du is a Professor at the Chinese University of Hong Kong. His research interests include e-business, data mining, collaborative commerce and the semantic web 